$2-2001$

\title{
Another Look at Hartford Civic Center Coliseum Collapse
}

Rachel Martin

Washington University in St Louis

Norbert J. Delatte

Cleveland State University, n.delatte@csuohio.edu

Follow this and additional works at: https://engagedscholarship.csuohio.edu/encee_facpub

Part of the Civil Engineering Commons, and the Structural Engineering Commons

How does access to this work benefit you? Let us know!

\section{Publisher's Statement}

(c) ASCE

\section{Original Citation}

Martin, R., and Delatte, N. (2001). "Another Look at Hartford Civic Center Coliseum Collapse."

J.Perform.Constr.Facil., 15(1), 31-36.

This Article is brought to you for free and open access by the Civil and Environmental Engineering at EngagedScholarship@CSU. It has been accepted for inclusion in Civil and Environmental Engineering Faculty Publications by an authorized administrator of EngagedScholarship@CSU. For more information, please contact library.es@csuohio.edu. 


\title{
Another look at Hartford Civic Center Coliseum Collapse
}

\author{
By Rachel Martin ${ }^{1}$ and Norbert J. Delatte, ${ }^{2}$ Member, ASCE
}

\begin{abstract}
Only a few hours after five thousand basketball fans had left, the roof of the Hartford Civic Center Coliseum collapsed under a heavy snowfall. Fortunately, the arena was empty. The design of the space frame roof had been based on an innovative and extensive computer analysis. However, when deflections twice as great as those predicted by the computer analysis were observed during construction, the warning was ignored. Overconfidence in computer analysis results played a large part in this failure. A useful lesson from this case is that the computer is only an analytical tool and computed results must be checked by the designer with a careful eye. The long, unbraced lengths of compression members made them highly susceptible to buckling. This case serves as a lesson for engineering students and practicing engineers concerning the difficult technical, professional, procedural, and ethical issues that may arise during the design and construction of a complex, highoccupancy structure.
\end{abstract}

\section{INTRODUCTION}

No one was killed or injured when the huge space truss roof of the empty Hartford Civil Center Coliseum collapsed under a heavy snowfall at 4:19 a.m. on January 18, 1978 (Fig. 1). Had the failure occurred just a few hours before, however, the death toll might have been hundreds, or even thousands. The dramatic roof, designed with the aid of computers, had shown evidence of distress during construction, but the warnings had not been heeded. The building had been in service for five years when it collapsed (Levy and Salvadori 1992).

For the engineer and engineering student, knowledge of engineering's failures is just as important as knowledge of its successes. A success illustrates what engineering can make possible, while a failure demonstrates its limits. It takes numerous successful structures to ensure the quality of a design or a construction method. One failure, however, can discredit an entire design or building technique. Because of this, the information that each failure has to offer should be carefully studied and applied to all future designs. As a result, similar failures, as well as their tragic consequences, can be avoided.

Because of their importance, failures should be incorporated into engineering education. Unfortunately, undergraduate engineering students receive little exposure to engineering failures in college. This approach to engineering education not only leaves students less prepared for what they will face after college, but it also fails to show the importance of continuing education (Delatte 1997). This may be one of the reasons that a 1983 survey of ASCE section and branch presidents found that engineering failures are all too common (Bosela 1993).

Since undergraduate engineering students already face an overcrowded curriculum, rather than requiring a new class covering failure case studies, these case studies can be incorporated into existing classes throughout a student's college career. Not only will this approach capture the students' interest by showing how their classes relate to engineering, but it will also inspire them to learn more about the history of the profession. In addition, it teaches them the importance of continued learning throughout their professional career. Finally, failure case studies provide a perfect opportunity to discuss ethical concerns, another neglected topic in engineering education, in real-life situations, as well as serving as a constant reminder of the repercussions of careless engineering (Delatte 1997).

According to a 1987 survey conducted by the Education Committee of the Technical Council on Forensic Engineering of the American Society of Civil Engineers, $63.2 \%$ of schools indicated that they would consider teaching a course on failure case studies if the appropriate materials were available. This clearly demonstrates the need for case study material and teaching aids to encourage the incorporation of failure case studies into the engineering curriculum (Rendon-Herrero 1993). The objectives of this paper are to:

1. Summarize what is known about the design, construction, and collapse of the Hartford Civil Center Coliseum.

2. Examine the causes of the failure as well as the legal ramifications.

3. Explore the technical, procedural, and ethical concerns present, focusing on how the failure could have been avoided and how to prevent similar failures in the future.

This failure case study can be integrated into engineering classes to introduce new topics or as the topic of a student research paper assignment.

\section{DESIGN AND CONSTRUCTION}

In 1970, Vincent Kling agreed to be the architect for the Hartford Civic Center. Shortly thereafter he hired Fraoli, Blum, and Yesselman, Engineers (FB\&Y), to design the arena. In order to save money, FB\&Y proposed an innovative design for the $91.4 \times 110 \mathrm{~m}(300 \times 360 \mathrm{ft})$ space frame roof 25.3

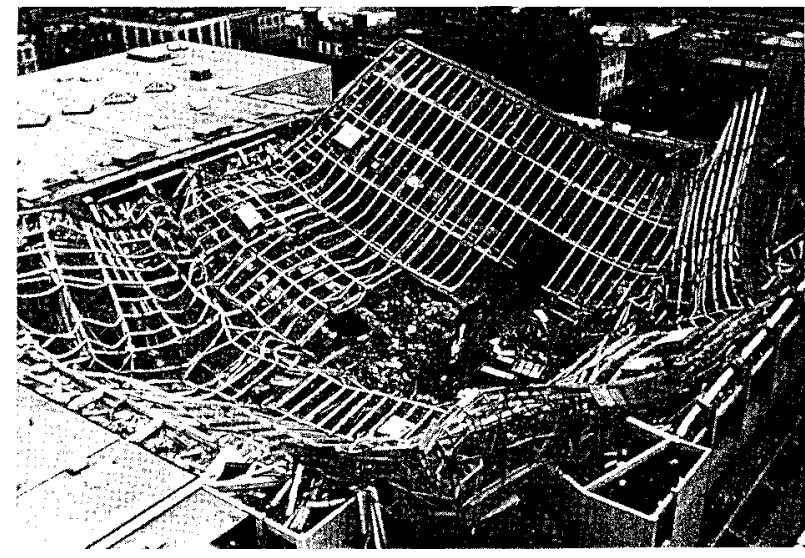

FIG. 1. Hartford Civic Center Coliseum Roof Collapse, 1978 (Construction Failure, Feld and Carper, (C) 1997. Reprinted by Permission of John Wiley \& Sons, Inc.) 
$\mathrm{m}(83 \mathrm{ft})$ over the arena. The proposed roof consisted of two main layers arranged in $9.14 \times 9.14 \mathrm{~m} \mathrm{(30}$ by $30 \mathrm{ft})$ grids composed of horizontal steel bars $6.4 \mathrm{~m}(21 \mathrm{ft})$ apart. Diagonal members $9.14 \mathrm{~m} \mathrm{(30} \mathrm{ft)} \mathrm{long} \mathrm{connected} \mathrm{the} \mathrm{nodes} \mathrm{of} \mathrm{the} \mathrm{upper}$ and lower layers and, in turn, were braced by an intermediate

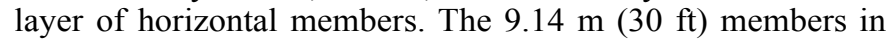
the top layer were also braced at their midpoint by intermediate diagonal members (Figs. 2 and 3).

This design departed from standard space frame roof design procedures in five ways:

1. The cross-section configuration of the four steel angles making up each truss member did not provide good resistance to buckling. The cross-shaped built-up section had a much smaller radius of gyration than either an I-section or a tube section configuration of the same structural members (Fig. 4). As a result, the buckling load for the cross-shaped section was much lower than that of the other configurations.

2. The top horizontal members intersected at a different point than the diagonal members rather than at the same point, making the roof especially susceptible to buckling because the diagonal members did not brace the top members against buckling.

3. The top layer of this roof did not support the roofing panels; short posts on the nodes of the top layer did. Not only were these posts meant to eliminate bending stresses on the top layer bars, but their varied heights also allowed water to be carried away to drains.

4. Four pylon legs positioned $13.7 \mathrm{~m} \mathrm{(45} \mathrm{ft)} \mathrm{inside} \mathrm{the}$

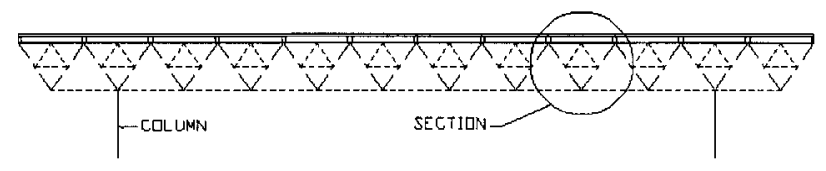

FIG. 2. Elevation of Space Frame Roof (Circled Section Is Shown Enlarged in Fig. 3)

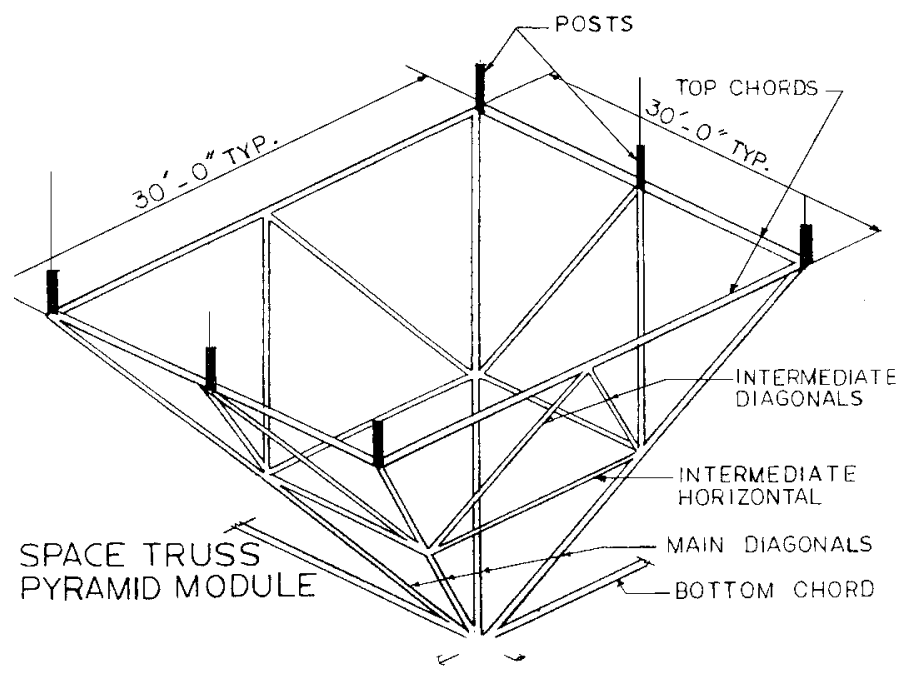

FIG. 3. Section of Space Frame Roof (Figure Courtesy of LZA Technology, from Lev Zetlin Associates, 1978, Reprinted by Permission)
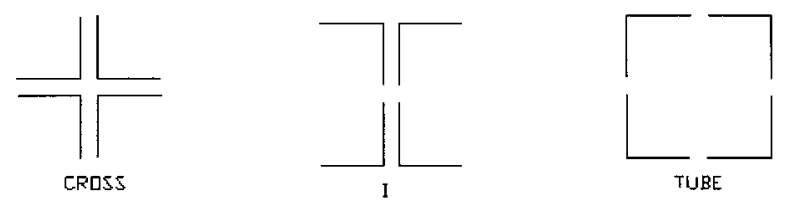

FIG. 4. Compression Member Configurations edges of the roof supported it instead of boundary columns or walls (Levy and Salvadori 1992).

5. The space frame was not cambered. Computer analysis predicted a downward deflection of $330 \mathrm{~mm}$ (13 in.) at the midpoint of the roof and an upward deflection of 150 $\mathrm{mm}$ (6 in.) at the corners ("Space" 1978).

Because of these money-saving innovations, the engineers employed state-of-the-art computer analysis to verify the safety of the building.

A year later construction began. To save time and money, the roof frame was completely assembled on the ground. While it was still on the ground the inspection agency notified the engineers that it had found excessive deflections at some of the nodes. Nothing was done.

After the frame was completed, hydraulic jacks located on top of the four pylons slowly lifted it into position. Once the frame was in its final position but before the roof deck was installed, its deflection was measured and found to be twice that predicted by computer analysis, and the engineers were notified. They, however, expressed no concern and responded that such discrepancies between the actual and the theoretical should be expected (Levy and Salvadori 1992).

When the subcontractor began fitting the steel frame supports for fascia panels on the outside of the truss, he ran into great difficulties due to the excessive deflections of the frame. Upon notification of this problem, the project manager "directed the subcontractor to deal with the problem or be responsible for delays." As a result, the subcontractor coped some of the supports and refabricated others in order to make the panels fit, and construction continued ("Design" 1978).

The roof was completed on January 16, 1973 (Feld and Carper 1997). The next year, a citizen expressed concern to the engineers regarding the large downward deflection he noticed in the arena roof, which he believed to be unsafe. The engineers and the contractor once again assured the city that everything was fine (Levy and Salvadori 1992).

\section{COLLAPSE}

On January 18, 1978, the Hartford Arena experienced the largest snowstorm of its five-year life. At 4:19 a.m., the center

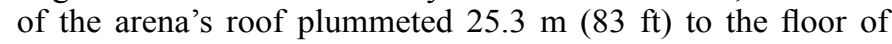
the arena, throwing the corners into the air. Just hours earlier the arena had been packed. Luckily, it was empty by the time of the collapse (Ross 1984).

\section{CAUSES OF FAILURE}

Hartford appointed a three-member panel to manage the investigation of the collaspe. This panel in turn hired Lev Zetlin Associates, Inc. (LZA), to ascertain the cause of the collapse and to propose a demolition procedure (Ross 1984). LZA issued its report later that year (Lev Zetlin Associates 1978). LZA discovered that the roof began failing as soon as it was completed due to design deficiencies. A photograph taken during construction showed obvious bowing in two of the members in the top layer.

Three major design errors, coupled with underestimation of the dead load by $20 \%$ [estimated frame weight $=0.862 \mathrm{~Pa}(18$ psf); actual frame weight $=1.10 \mathrm{~Pa}(23 \mathrm{psf})]$, allowed the weight of the accumulated snow to collapse the roof ("Design" 1978). The load on the day of collapse was 3.16-3.50 $\mathrm{Pa}$ (66-73 psf), while the arena should have had a design capacity of at least 6.70 Pa (140 psf) ("Collapsed" 1978b). The three design errors responsible for the collapse are listed below:

- The top layer's exterior compression members on the east and the west faces were overloaded by $852 \%$. 
- The top layer's exterior compression members on the north and the south faces were overloaded by $213 \%$.

- The top layer's interior compression members in the eastwest direction were overloaded by $72 \%$.

In addition to these errors in the original design, LZA discovered that no midpoint braces were provided for the members in the top layer. The exterior members were only braced every $9.14 \mathrm{~m}(30 \mathrm{ft})$, rather than the $4.57 \mathrm{~m}(15 \mathrm{ft})$ intervals specified, and the interior members were only partially and insufficiently braced at their midpoints. The two members attached to the midpoint of the top chord were both in the same plane as the long axis of the chord, so they only provided bracing in one direction. The perpendicular direction was ef-

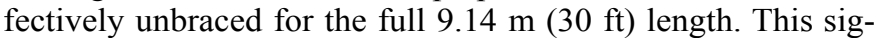
nificantly reduced the load that the roof could safely carry. In addition, certain perimeter top chord members with a post landing at midpoint were subjected to bending stress from the roof load applied through the post. Since the members were not designed for bending, this led to a considerable overstress (Lev Zetlin Associates 1978).

Fig. 5 and Table 1 compare some of original details to actual designs used in the building, demonstrating the reduction in strength that these changes caused. Connection A was typically used on the east-west edges of the roof, while connection B was used on the north-south edges. Most of the interior members used connection $\mathrm{C}$, while a few used connection $\mathrm{D}$. The key difference between the original and the as-built details may be seen in Fig. 5 and also by comparing the top and bottom rows of the table. The diagonal members were attached some distance below the horizontal members. Thus, the flexibility of the connection reduced the effectiveness of the bracing by introducing a "spring brace" instead of the hard brace that had been assumed.

The most overstressed members in the top layer buckled under the added weight of the snow, causing the other members to buckle. This changed the forces acting on the lower layer from tension to compression, causing them to buckle also in a progressive failure. Two major folds formed initiating the collapse ("Design" 1978). These were not the only errors that LZA discovered. Listed below are the other factors that contributed to, but probably were not solely responsible for, the collapse:

- The slenderness ratio of the built-up members violated the American Institute of Steel Construction (AISC) code provisions. The spacer plates separating the individual angles were placed too far apart in some of the four-angle members, allowing individual angles to buckle.

- The members with bolt holes exceeding $85 \%$ of the total area violated the AISC code requirements for section reduction of tension members ("Collapsed" 1978b).

- There were misplaced diagonal members (Feld and Carper 1997).

Loomis and Loomis, Inc., also investigated the Hartford collapse. They agreed with LZA that gross design errors were responsible for the progressive collapse of the roof, beginning the day that it was completed. They, however, believed that the torsional buckling of the compression members, rather than the lateral buckling of top chords, initiated the collapse.

Using computer analysis, Loomis and Loomis found that the top truss members and the compression diagonal members near the four support pylons were approaching their torsional buckling capacity the day before the collapse. An estimated $0.575-0.718 \mathrm{~Pa}(12-15 \mathrm{psf})$ of live load would cause the roof to fail. The snow from the night before the collapse comprised a live load of $0.670-0.910 \mathrm{~Pa}(14-19 \mathrm{psf})$. Because torsional
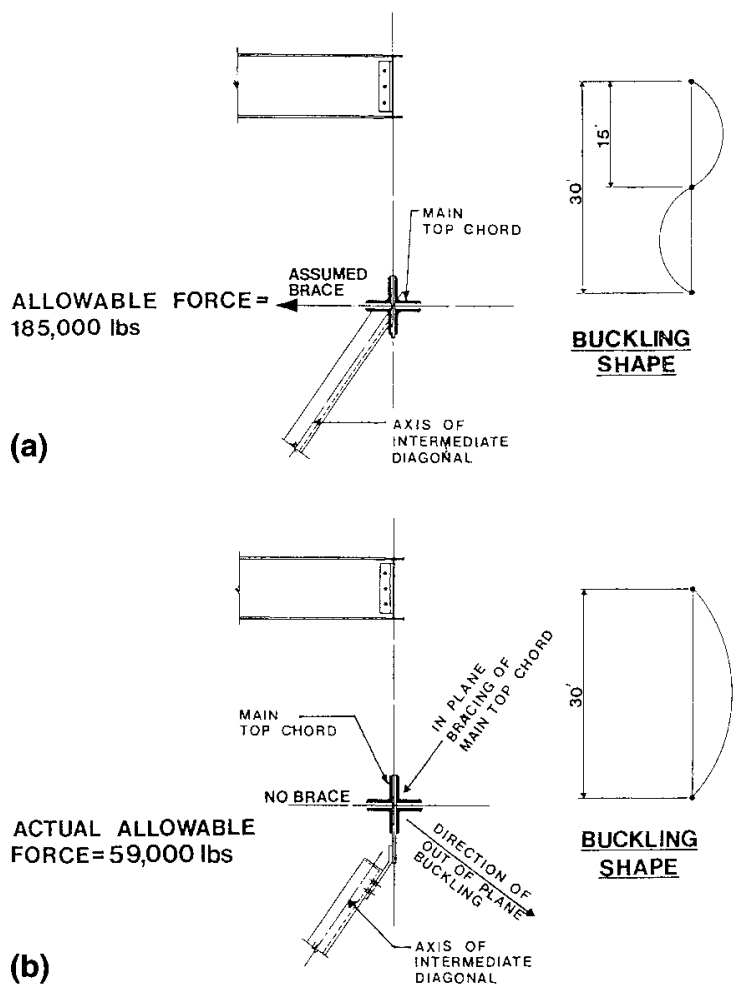

TOP CHORD EAST-WEST DIRECTION

FIG. 5. Comparison of Actual and Assumed Bracing (Figure Courtesy of LZA Technology, from Lev Zetlin Associates, 1978, Reprinted by Permission): (a) Original Design Assumption; (b) Actual Design Condition

buckling is uncommon, it is often an overlooked mode of failure ("New" 1979).

Hannskarl Bandel, a structural consultant, completed an independent investigation of the collapse for the architect's insurance company. He blamed the collapse on a faulty weld connecting the scoreboard to the roof. This opinion conflicts with the opinions of all the other investigators ("Hartford" 1979). The LZA report's findings were also disputed by FB\&Y ("Collapsed" 1978a).

\section{LEGAL REPURCUSSIONS}

Six years after the collapse, all of the parties reached an out-of-court settlement. While this was beneficial to the parties involved, it did not provide the engineering profession with the precedents that such a case could set (Feld and Carper 1997).

\section{TECHNICAL ASPECTS}

The engineers for the Hartford Arena depended on computer analysis to assess the safety of their design. Computer programs, however, are only as good as their programmer and may tend to offer engineers a false sense of security (Shepherd and Frost 1995). The LZA report noted "the computer model used by the structural engineer only included the top and bottom chords and the main diagonals. Roof loads were only applied at top chord main panel points. If the computer model had represented the intermediate diagonals and horizontals and had included the roof loads at the midpoint, subpanel points at the top chord, the instabilities and primary bending moments would have been detected by the designer" (Lev Zetlin Associates 1978).

Instead of the cruciform shape of the rods, a tube or I-bar configuration would have been more stable and less suscepti- 


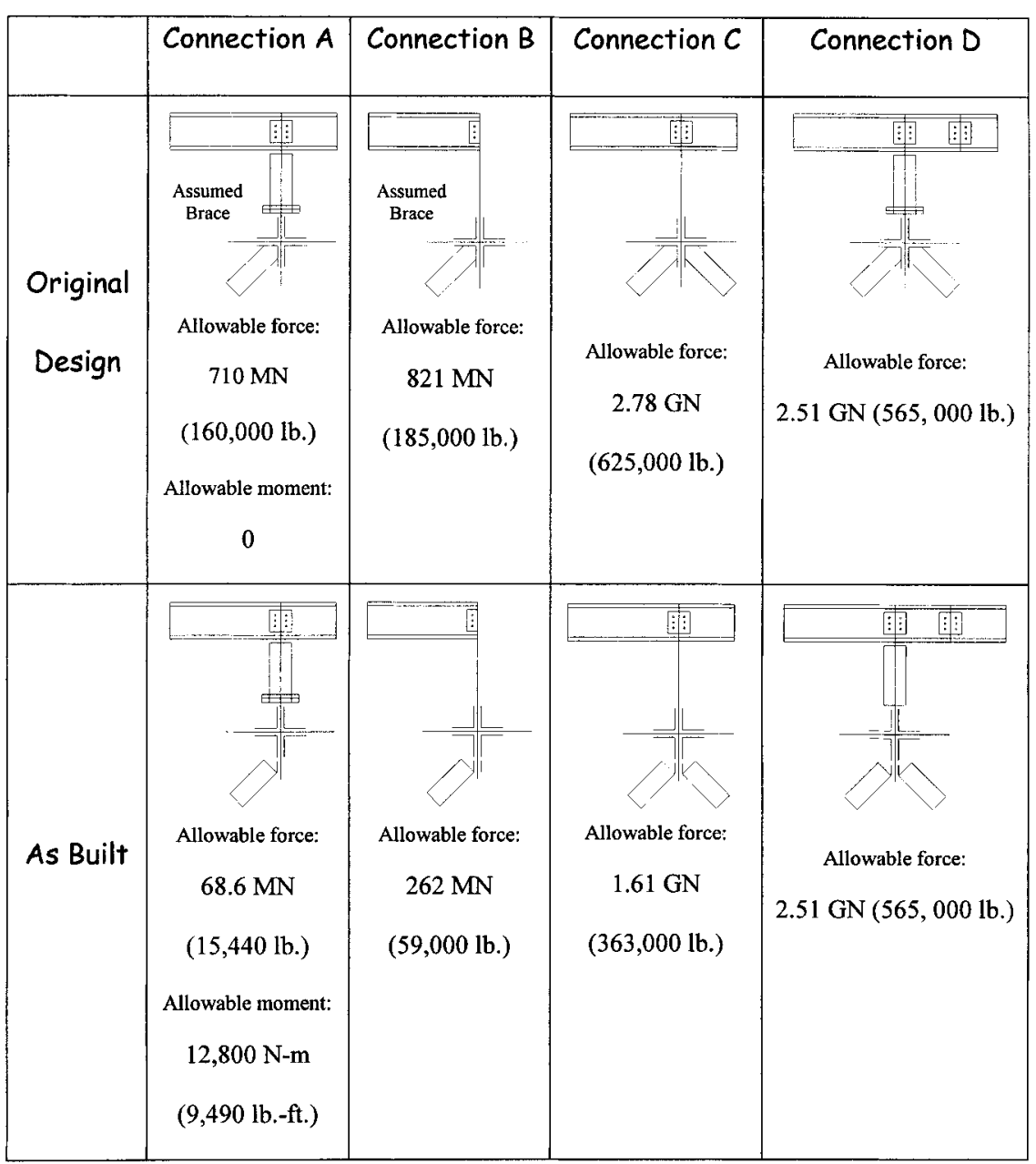

*Drawings by Rachel Martin based on information from ENR, April 6, 1978

ble to bending and twisting. The cruciform shape has the advantage of making the members easier to connect. Also, if the horizontal and diagonal members intersected at the same place, the bracing would have increased the buckling capacity in these members. The LZA report noted that "apparently, the choice of the typical member as a cruciform, a section that is weak in bending and torsion, was based on the design assumption that such bending and torsion would be negligible in the space truss" (Lev Zetlin Associates 1978).

The LZA report further noted that "the investigation confirms that space trusses and/or space frames are valid and safe structural systems. Two-way space trusses have been employed successfully on many projects. In the case of the Hartford Coliseum, unfortunately, certain aspects of the design and construction were not implemented correctly" (Lev Zetlin Associates 1978).

\section{PROFESSIONAL AND PROCEDURAL ASPECTS}

The Hartford Arena contract was divided into five subcontracts coordinated by a construction manager. Not only did this fragmentation allow mistakes to slip through the cracks, it also left confusion over who was responsible for the project as a whole. Even though the architect recommended that a qualified structural engineer be hired to oversee the construction, the construction manager refused, saying that it was a waste of money and that he would inspect the project himself. After the collapse he disclaimed all responsibility on the grounds that a design error had caused the collapse. He asserted that he was only responsible for ensuring that the design was constructed correctly and not the performance of the project (p. 202, Feld and Carper 1997).

It is important for responsibility for the integrity of the entire project to rest with one person. Feld and Carper (pp. 202$204,1997)$ offer an excellent discussion of the role that procedural deficiencies played in this collapse.

As a result of the construction manager's refusal to hire a structural engineer for the purpose of inspection, no one realized the structural implications of the bowing members. This collapse illustrates the importance of having a structural engineer, especially the designer, perform the field inspection. The designer understands the structure that is being built and would best be able to recognize the warning signs of poor structural performance and rectify them before they grow to catastrophic proportions. The LZA report noted "the inspection and/or quality control procedures utilized ... were inadequate and poorly handled. The absence of a full-time registered structural engineer experienced with the design and construction of long-span special structures was a serious mistake. The visually apparent distortion or bowing of exterior top chord members should have been a red flag to one of the inspecting parties that there was something seriously wrong with the Hartford Coliseum space truss structure" (Lev Zetlin Associates, 1978).

Finally, the Hartford department of licenses and inspection did not require the project peer review that it usually required for projects of this magnitude. If a second opinion had been obtained, the design deficiencies responsible for the arena's 
collapse probably would have been discovered (Lev Zetlin Associates 1978). Peer reviews are an essential safety measure for high-occupancy buildings and structures experimenting with new design techniques (Feld and Carper 1997). Today, Connecticut is one of the few states that requires peer review of certain buildings.

\section{ETHICAL ASPECTS}

The excessive deflections apparent during construction were brought to the design engineer's attention several times. The engineer, confident in his design and the computer analysis that confirmed it, ignored these warnings and did not take the time to recheck his work. The engineer should pay close attention to unexpected deformations and investigate their causes. They often indicate structural deficiencies and should be investigated and corrected immediately. Unexpected deformations provide a clear signal that the structural behavior is different from that anticipated by the designer.

Kaminetzky (1991) quotes at length from a story in The Philadelphia Inquirer from May 28, 1978, about this incident, headlined "Why The Roof Came Tumbling Down." The story suggests that the ironworkers knew from observing the deformations during construction that the building was a death trap and had vowed never to enter it once it was completed. It also questions why the workers' warnings were not listened to.

Also, this collapse raises the important question of whether the factor of safety should be increased for buildings with a high occupancy. Should the impact of a possible failure be taken into account in determining the factor of safety (Kaminetzky 1991)?

\section{EDUCATIONAL ASPECTS}

Petroski discusses this case in terms of the need for engineers to be able to reason out whether or not computer results make sense, through hand calculations and knowledge of structural behavior and performance. "Because the computer can make so many calculations so quickly, there is a tendency now to use it to design structures in which every part is of minimum weight and strength, thereby producing the most economical structure. This degree of optimization was not practical to expect when hand calculations were the norm, and designers generally settled for an admittedly overdesigned and thus a somewhat extravagant, if probably extra-safe, structure. However, by making every part as light and as highly stressed as possible, within applicable building code and factor of safety requirements, there is little room for error-in the computer's calculations, in the part manufacturers' products, or in the construction workers' execution of the design. Thus, computer-optimized structures may be marginally or least-safe designs, as the Hartford Civil Center roof proved to be" (p. 199, Petroski 1985). In the decade and a half since Petroski wrote these words, despite tremendous advances in computing power and software, there is no sign that computer programs will soon be able to envision failure modes that the designer has not foreseen, or check their own work.

Failure plays an important role in engineering practice. Through failure analysis, engineers can learn to avoid similar technical errors, allowing them to build stronger, safer structures. Since failure analysis plays such an integral role in a good engineer's professional career, it only makes sense that, in college, engineering students should be taught about failures, as well as their importance to any engineer's professional life. In light of an already overcrowded undergraduate engineering curriculum, integrating failure case studies into already existing engineering classes is the most logical solution.

This approach gives students a better idea of the obstacles that will face them after college, in addition to demonstrating how the theoretical ideas taught in their classes are actually applied by engineers. The only real obstacle that lies in the way of increased failure awareness at the undergraduate level is the absence of adequate resources, such as well-developed failure case studies and appropriate illustrations. This paper provides professors and students with a failure case study that can be integrated into undergraduate classes.

How can educators use these aspects of this case? In structural analysis courses, they can be used to address technical topics such as safety during construction, load paths, stability of incomplete structures during construction, and stability of structural members. Students may be assigned to research the literature in greater depth and support or criticize the available theories. For engineering students, the legal ramifications of the case may be of even greater interest. Three additional important points that may be made are the importance of fixing overall responsibility on a project before difficulties are encountered, the need for inspection during construction, and the need to read the literature of the profession to keep up with technical and procedural advances.

As a class example or homework problem, students may compare the moment of inertia for the cruciform, $I$, and the tube configurations of four angles, as shown in Fig. 3. Angle legs ranged from 89 to $203 \mathrm{~mm}$ (3 1/2 to $8 \mathrm{in}$.) long and were 8 to $22 \mathrm{~mm}(5 / 16$ to $7 / 8$ in.) thick depending on loads, and the angles were separated by spacers 19 to $22 \mathrm{~mm} \mathrm{(3/4} \mathrm{to}$ $7 / 8$ inch) (Lev Zetlin Associates 1978). For numerical examples, $127 \times 127 \times 8 \mathrm{~mm}$ angles $(\mathrm{L} 5 \times 5 \times 5 / 16)$ may be used. The torsional stiffness of these configurations may also be calculated and compared.

\section{CONCLUSIONS}

A useful lesson from this case is that computer software is only an analytical tool and that computed results must be checked by the designer with a careful eye. Users must understand the theoretical foundations of the programs and the associated limitations. This case serves as a lesson for engineering students and practicing engineers concerning the difficult technical, professional, procedural, and ethical issues that may arise during the design and construction of a complex, high-occupancy structure. There is no substitute for a thorough knowledge of structural behavior, coupled with a healthy skepticism toward the completeness and accuracy of computer software solutions to unusual problems.

\section{ACKNOWLEDGMENTS}

This research was supported by the National Science Foundation as part of the University of Alabama at Birmingham Research Experiences for Undergraduates Site in Structural Engineering under grant EEC9820484. Thanks are due to David Peraza of LZA Technology for providing a copy of the firm's 1978 investigation report to the City of Hartford. The paper reviewers made many excellent suggestions that were incorporated into the final version of this manuscript.

\section{APPENDIX. REFERENCES}

Bosela, P. (1993). "Failure of engineered facilities: academia responds to the challenge." J. Perf. Constr. Fac., ASCE, 5.

“Collapsed roof design defended." (1978a). ENR, June 29.

"Collapsed space truss roof had a combination of flaws." (1978b). ENR, June 22.

Delatte, N. J. (1997). “Integrating failure case studies and engineering ethics in fundamental engineering mechanics courses." J. Profl. Issues in Engrg. Educ. and Pract., ASCE, 123(3), 111-116.

"Design flaws collapsed steel space frame roof." (1978). ENR, April 6.

Education Committee of the Technical Council on Forensic Engineering. (1995). Failures in civil engineering: structural, foundation, and geoenvironmental case studies, R. Shepherd and D. Frost, eds., ASCE, New York.

Feld, J., and Carper, K. (1997). Construction failure, 2nd Ed., Wiley, New York. 
"Hartford collapse blamed on weld." (1979). ENR, June 24.

Kaminetzky, D. (1991). Design and construction failures: Lessons from forensic investigations, McGraw-Hill, New York.

Lev Zetlin Associates. (1978). Rep. of Engrg. Investigation Concerning Causes of Collapse of Hartford Coliseum Space Truss Roof on January 18, 1978, Hartford, Conn.

Levy, M., and Salvadori, M. (1992). Why buildings fall down: how structures fail, W. W. Norton, New York.
"New theory on why Hartford roof fell." (1979). ENR, June 14.

Petroski, H. (1985). To engineer is human, St. Martins Press, New York. Rendon-Herrero, O. (1993). "Too many failures: what can education do?" J. Perf. Constr. Fac., ASCE, 7(2), 133-139.

Ross, S., et al. (1984). "Hartford Civic Center, 1978." Construction disasters, McGraw-Hill, New York.

"Space frame roofs collapse following heavy snowfalls." (1978). ENR, January 26. 